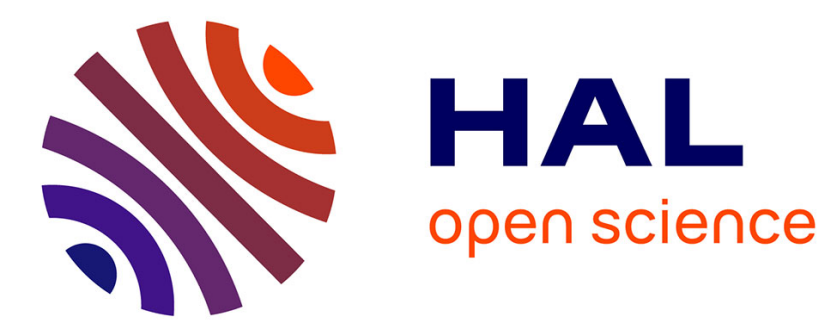

\title{
Process of crystallization of polymers at low supercooling
}

J. Rault

\section{To cite this version:}

J. Rault. Process of crystallization of polymers at low supercooling. Journal de Physique Lettres, 1978, 39 (21), pp.411-413. 10.1051/jphyslet:019780039021041100 . jpa-00231530

\section{HAL Id: jpa-00231530 https://hal.science/jpa-00231530}

Submitted on 1 Jan 1978

HAL is a multi-disciplinary open access archive for the deposit and dissemination of scientific research documents, whether they are published or not. The documents may come from teaching and research institutions in France or abroad, or from public or private research centers.
L'archive ouverte pluridisciplinaire HAL, est destinée au dépôt et à la diffusion de documents scientifiques de niveau recherche, publiés ou non, émanant des établissements d'enseignement et de recherche français ou étrangers, des laboratoires publics ou privés. 
Classification Physics Abstracts $61.50 \mathrm{C}-81.20 \mathrm{~S}$

\title{
PROCESS OF CRYSTALLIZATION OF POLYMERS AT LOW SUPERCOOLING
}

\author{
J. RAULT \\ Laboratoire de Physique des Solides, Université Paris-Sud, 91405 Orsay, France
}

(Reçu le 26 juin 1978, révisé le 13 septembre 1978, accepté le 15 septembre 1978)

\begin{abstract}
Résumé. - L'épaisseur des lamelles cristallines des polymères dépend en général de la surfusion $\Delta T$. Un processus de cristallisation à deux étapes est proposé pour expliquer la loi observée entre $l$ et $\Delta T$. Les deux étapes en parallèle sont : a) une cristallisation initiale conduisant à des lamelles d'épaisseur constante ne dépéndant que de la rigidité de la chaîne à l'état liquide juste avant la cristallisation; $b$ ) puis un épaississement. Ce dernier processus est d'autant plus important que la chaîne est plus mobile dans l'état solide.
\end{abstract}

\begin{abstract}
The fold length of crystalline polymer depends in general on the supercooling $\Delta T$. The observed law between $l$ and $\Delta T$ is explained by a process of cristallization in two consecutive stages : $a$ ) a collapse of the chain with a constant fold length, characteristic of the chain in the liquid state and $b$ ) an annealing of the crystal for a short time. The process $b$ is important for polymers which present a high mobility of the chain in the solid state.
\end{abstract}

The starting point of the various kinetic theories [1-4] of crystallization of polymers is that the growth process is secondary nucleation controlled. The application of nucleation theories is suggested by the strongly negative temperature coefficient of the growth rate and by the fact that the thickness $l$ of the crystalline lamellae formed from dilute solution as from the melt decreases when the supercooling increases.

These kinetic theories give a fold length $l$ of the form :

$$
l=2 \sigma_{\mathrm{e}} \frac{T_{\mathrm{m}}^{0}}{\Delta H \cdot \Delta T}+\delta l
$$

$\sigma_{\mathrm{e}}$ is the end surface free energy

$T_{\mathrm{m}}^{0}$ the melting or dissolution temperature of the infinitely extended chain crystal

$\Delta T$ is the supercooling, $\Delta H$ is the heat of fusion and

$\delta l$ is an additional term which diverges at high supercooling.

In fact, the experimental law between the fold length and the supercooling $\Delta T$ is of the form [5] :

$$
l=l_{\mathrm{c}}\left[1+\frac{\alpha}{\Delta T}\right]
$$

The physical meaning of $l_{\mathrm{c}}$, the limiting fold length has been previously reported $[6,7] . l_{\mathrm{c}}$ is a characte- ristic parameter of the polymer, which depends only on the rigidity of the chain just before crystallization. At high supercooling, the thickness of the lamella is about of the same order of magnitude as the mean length of the loops formed by the liquid chain just before crystallization.

The aim of this note is to give a physical meaning for the term $\alpha$ in relation (2).

Let us suppose that there are two stages in the formation of the monocrystal :

a) The initial stage of crystallization [6] is the collapse of the chain on itself, or on the surface of a crystal leading to a fold length equal to $l_{\mathrm{c}}$ whatever is the temperature of crystallization.

b) Then, the crystal thickens near the growth faces. This is an annealing effect at the crystallization temperature, the fold length of a chain will stop increasing when the chain is located at a distance $\Delta x$, a few lattice parameters, from the growth face after further crystal growth (Fig. 1).

The two stage process is suggested by the form of relation (2). Only stage $a$ exists for certain polymers like nylons, polyurethane, amylose, etc. Stage $b$ is suggested by this general rule :

The temperature range where the lamella thickness is dependent on the temperature of crystallization is the same order of magnitude as that where thickening by annealing appears. 


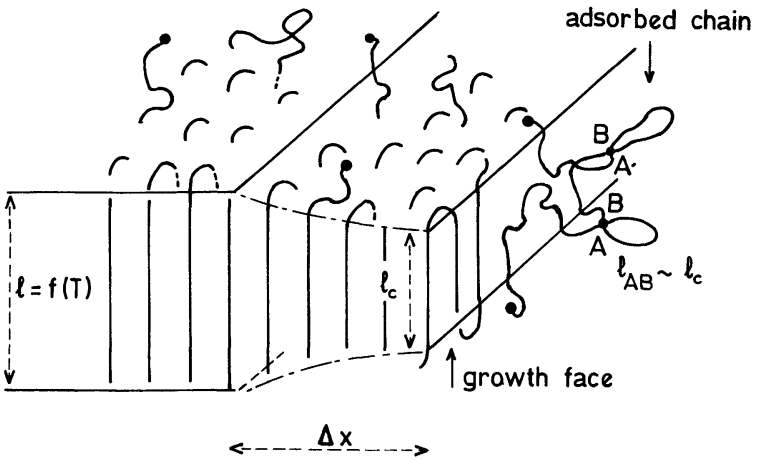

FIG. 1. - Model of crystallization : the chain in the adsorbed layer on the growth face collapses on itself and on the surface with a constant fold length, depending on the mean length of the loop of the chain in the liquid state, and then the fold length of that chain will increase by annealing at the temperature of crystallization during a time $\Delta t$.

An extreme case is nylon, this polymer shows no variation of the crystalline thickness $l$ with the temperature of crystallization, and no thickening by annealing (Fig. 2).

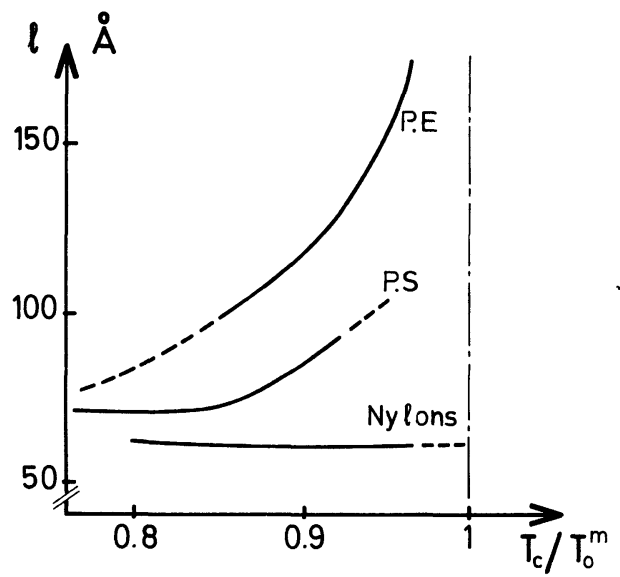

FIG. 2. - Dependence of the fold length in polyethylene (P.E.), polystyrene (P.S.) and nylons crystallized from solution as a function of the reduced temperature of crystallization $T_{\mathrm{c}} / T_{0}^{\mathrm{m}}[5,10,11]$. The limiting fold length $l_{\mathrm{c}}$ of these polymers are of the same order of magnitude. At high supercooling process $b$ is not operative.

In crystal growing from melt or from solution, there is a competition between the lamella thickening and the perfection of the crystal. In bad crystal near the growth face, thickening is operative : edge dislocations can nucleate easily at the edge and initiate the thickening [8], the lattice is deformed by various defects [9]. Therefore the chains near the edge are more mobile than the chains far from the edge in a good crystal. The growth rate of polymer monocrystal is independent of the size of the monocrystal, therefore the time $\Delta t$ for a chain at the growth face to be covered by a layer $\Delta x$ of other chains is constant. The time of annealing $\Delta t$ is equal for all the parts of the crystal.

As noted by Peterlin [12], we may neglect the nucleation process for crystal thickening and consider only the energy barrier for collective jump of a stem of length $l$ equal to the lamella thickness. The activation energy for such a jump is $\Delta F=\frac{l}{a_{0}} E_{\mathrm{m}}$. $E_{\mathrm{m}}$ is the activation energy for the jump of one group of the backbone between two consecutive equilibrium positions separated by a distance $a_{0}$. The probability of this jump is proportional to exp $-\Delta F / k T$, therefore

$$
\frac{\mathrm{d} l}{\mathrm{~d} t}=A \exp -\frac{l}{a_{0}} E_{\mathrm{m}} \frac{1}{k T} .
$$

This gives the law of thickening, observed by Fisher and Schmidt [13] :

$$
l=l_{0}[1+B \log (\Delta t+c)]
$$

$l_{0}$ and $c$ are constants and $B l_{0}=\frac{k T}{E_{\mathrm{m}}} \cdot a_{0}$.

These constants depend on the annealing process, on the solvent and they depend on the location of the chains in the crystal. In solution grown crystals annealed for a long time compared to the time of crystallization there is no thickening, therefore, the chain jump inside the crystal is not in that case an operative process. During crystallization the process of thickening is assumed to be operative for the chains near the border of the crystal, during only a small time $\Delta t$ compared to the time of crystallization (Fig. 2).

The growth rate of the monocrystal near the temperature of dissolution $T_{0}^{\mathrm{m}}$, or maximum temperature of crystallization is [5] :

$$
V=\frac{\Delta x}{\Delta t}=G_{0} \exp -\frac{\Delta G}{k T}
$$

where $G_{0}$ is a constant depending on the molecular weight and

$$
\Delta G=\frac{4 \sigma \sigma_{\mathrm{e}} b_{0} T_{\mathrm{m}}}{\Delta H . \Delta T}
$$

$\sigma$ is the surface free energy of the growth face.

Putting $\Delta t$ of relation (4) into relation (3) we obtain for $\Delta t>c$

$$
l=l_{0}\left(1+B \cdot \beta \cdot \frac{2 \sigma_{\mathrm{e}} T_{\mathrm{m}}}{\Delta H . \Delta T}+\delta l\right)
$$

$\delta l$ is equal to $B \log \frac{\Delta x}{G_{0}}$ and negligible compared to the second term which predominates at low supercooling. $\beta$ is equal to $\frac{2 \sigma b_{0}}{k T}$.

For polyethylene $l_{0} B=10 \AA$ far from the melting temperature [12] and $\beta=\frac{1}{10} \AA^{-1}$; thus relation (2) is obtained. We obtain the same temperature depen- 
dence as that of relation (1) given by the kinetic theories.

Conclusion. - The observed dependence of the fold period with the temperature of crystallization is explained better by annealing phenomena, rather than by kinetic theories of crystallization. It is worthwhile noting that in our model, it is obvious that polymers like nylon which do not show thickening by annealing, show no variation of the fold length with the temperature [10], the barrier energy $E_{\mathrm{m}}$ for stem jump being too high because of hydrogen bonding between consecutive chains with the term $B$ in relation (5) and the term $\alpha$ in relation (2) too low. Inversely, this model explains why for an inert chain with a very simple backbone like polyethylene, the fold length presents great variation with the supercooling. The barrier energy is very small, and therefore the chain very mobile. Polystyrene [11] has a behaviour intermediate between polyethylene and nylons; the benzene ring decreases the mobility of the chain, but not as much as hydrogen bonding between consecutive chains (Fig. 2).

The relations (2) and (5) describing the morphology of polymer crystals depend only on two parameters, the rigidity of the chain, in the liquid state just before crystallization, and the mobility of the chain in the crystal lattice. This latter parameter depends on the dynamic flexibility of the chain, and on the interaction between different chain groups in the crystal.

Finally, we must emphasize that relation (5) accounts for the behaviour of polyethylene crystallized at high pressure and high temperature in the hexagonal structure. The distance between consecutive chains and therefore the mobility of the chain are greater in that phase than in the orthorhombic phase. The annealing effects and the parameter $B$ in relation (5) are enhanced, which explains the formation of extended chain crystals.

\section{References}

[1] Lauritzen, J. I., Hoffman, J. D., J. Res. Nat. Bur. Stand. A 64 (1960) 73.

[2] Lauritzen, J. I., Passaglia, E., J. Res. Nat. Bur. Stand. A 64 (1960) $73 ; 71$ (1967) 261.

[3] Frank, F. C., Tosi, M., Proc. R. Soc. (London) A 263 (1961) 323.

[4] Price, F. P., J. Chem. Phys. 35 (1961) 1884.

[5] Wunderlich, B., Macromolecular Physics (Acad. Press) 1974.

[6] Rault, J., C.R. Hebd. Séan. Acad. Sci. Paris, 285B (1977) 321.
[7] Rault, J., J. Macrom. Sci. Phys. 15 (4) (1978) 735.

[8] Rault, J., J. Macrom. Sci. Phys. B 12 (1976) 335.

[9] Keller, A., Prog. Phys. 31 (1968) 623.

[10] Dreyfus, P., Keller, A., J. Polym. Sci. A 2 (1973) 11, 193.

[11] Jones, D. H., Latham, A. J., Keller, A., Girolamo, M., J. Polym. Sci. Phys. 11 (1973) 1759.

[12] Peterlin, A., Polym. Lett. 1 (1963) 279.

[13] Fischer, E. W., Schmidt, G., Angew. Chem. 74 (1962) 551. 